\title{
RESEARCH ON THE STABILITY OF MULTI-DGS SYSTEM
}

\author{
Zhuo Chen, Xuanqun Tang, Hongjun Zhang, Qingfang Zhang, Yan Liu
}

Original scientific paper

This paper presents an improved model of multi-DGs system for enhancing the stability. The distributed generations (DGs) in the system are equipped with the additional active power controller as the technique of enhancing the wind-thermal-bundled system stability. Firstly, the influence of multi-DGs system on the oscillation of the system is analysed. Then, the conditions for DGs producing positive damping to the power system are obtained. Secondly, taking the wind farm as the study object, the increment of the frequency of the point of common coupling (PCC) in the wind farm is feedback to the active control loops for regulating the active power of wind turbine. At the same time, the multi-DGs system holds a positive damping effect on the power system which enables the dynamic behaviour of the wind farm to be improved. Thirdly, the effect of time delay on control performance is further considered and two propositions for solving critical time-delay are put forward and proved, which are used as the constraint condition of additional active power control. Finally, the time domain simulation is implemented and the correctness of the proposed method is verified by the root locus analysis and frequency domain simulation. The results show that the additional active power control can significantly enhance the power system damping. However, the wind farm will provide negative damping and even the whole system will not maintain the power angle stability when the time-delay increases and exceeds the critical time-delay.

Keywords: anti-islanding; critical time-delay; multi-DGs system; power system damping; wind farm

\section{Istraživanje stabilnosti Multi-DGs sustava}

Izvorni znanstveni članak

U radu se daje poboljšani model multi-DGs sustava za poboljšanje stabilnosti. Distribuirana proizvodnja (DGs) u sustavu opremljena je dodatnim regulatorom snage kao metodom za poboljšanje stabilnosti vjetro-toplinskog višežilnog sustava. Najprije se analizira utjecaj multi-DGs sustava na oscilacije sustava. Tada se postižu uvjeti da DGs stvaraju pozitivno prigušenje energetskog sustava. Zatim, uzmajući vjetroelektranu za predmet istraživanja, porast frekvencije točke zajedničkog spajanja (PCC) u vjetroelektrani je povratna informacija za aktivne upravljčke petlje za reguliranje aktivne snage vjetroturbine. U isto vrijeme multi-DGs sustav zadržava pozitivan učinak prigušenja na energetski sustav koji omogućuje poboljšanje dinamičkog ponašanja vjetroelektrane. Kao treće, razmatra se učinak vremenskog kašnjenja na funkcioniranje sustava upravljanja te se razmatraju dokazuju dva prijedloga za rješenje vremenskog zastoja, smatrajući ih ograničenjem za dodatno aktivno upravljanje snagom. Konačno, implimentira se simulacija vremenskog područja i provjerava se točnost predložene metode pomoću root locus analize i simulacije vremenskog područja. Rezultati pokazuju da dodatni regulator snage može značajno poboljšati prigušenje energetskog sustava. Ipak, vjetroelektrana će imati negativno prigušenje i cijeli sustav čak ne će održati stabilnost snage kad dođe do povećanja vremenskog zastoja i kad se prekoraći kritični vremenski zastoj.

Ključne riječi: anti-islanding; kritični vremenski zastoj; multi-DGs sustav; prigušenje energetskog sustava; vjetroelektrana

\section{Introduction}

Multi-DGs system is a system in which a number of distributed power generations (DGs) are combined with technological advancement in distribution electronic system [1, 2]. These DGs in the system can produce substantial clean energy and alleviate energy crisis. Many types of DGs such as wind turbine generators, fuel-cells, PV cells and micro-turbines are interfaced to the distribution electronic system through power electronic converters [3]. With the expansion of wind power, the impact of wind power on the synchronous power grid is becoming more and more significant. When the largescale wind power is delivered into the power transmission system, the dynamic behaviour and stability mechanism of the whole power system will have significant change [4]. One of the most important problems is that the damping characteristics of the system may be significantly weakened. In recent years, the effects of wind farm on the damping of the system have attracted much attention $[5 \div 7]$.

The influence of wind farms composed of different types of wind turbines on the damping of the system was analysed by examples. The results showed that when the capacity of the wind farm is large, the conventional asynchronous wind turbines enhance the system damping but the doubly fed wind turbines obviously reduce the damping of the system [8]. While the oscillation mode is strongly related to the wind turbines, the oscillation of the system is restrained. But when the oscillation mode is strongly related to the synchronous generators, the damping of the system is practically unaffected [9]. Literature $[10,11]$ considered that the wind load has little effect on the damping when the wind power ratio is about $16 \%$; after the introduction of PSS control unit, the wind farm composed of double fed induction generators (DFIG) can improve system damping, and the improvement degree for the damping is determined by the operation state of DFIG and the active power output. The torque method was adopted in [10] to study the influence of DFIG on the damping characteristics of the power system and to present improvement measures. Also the influence mechanism of the wind farm with DFIG on the transient stability of the power system was analysed. In order to ensure the safe operation of the grid connected to the wind farm, various control strategies and control methods were proposed to improve the damping characteristics of the power system in $[11 \div 14]$.

However, there are two key issues that were not well addressed in the previous studies: 1) The analytical conditions for the positive impact of wind farms on the damping of the system were not given explicitly; 2) When the additional control is carried out, the problems about time-lag caused by wide area communication network were not considered. Aiming at the above problems, starting from the damping characteristic of the thermalwind-bundled system, this paper studies damping effect of wind farm on the system oscillation and derives the 
analytical conditions for providing positive damping of wind farms. In order to achieve the condition, additional active power control strategy for wind farm is proposed, and the influence of the time-delay of the control signal is analysed deeply. Moreover, the propositions relating to the range of time-lag in additional active power controller are put forward and proved. In addition, the correctness of the proposed propositions is verified by simulation analysis.

This paper is organized as follows: section 2 completes the model of the multi-DGs system and explains the principle of damping system oscillation; a novel control strategy of the multi-DGs system is proposed and the technical measures and existing problems are discussed in section 3.Then the influence of control time-lag on the controller of DGs is analysed in detail in section 4 . In section 5, the critical time-delay is presented and the methods about calculating the time-lag are raised. After that, a system with the multi-DGs is used as the simulation case to prove the correctness of the method mentioned in this paper. Finally, the conclusion and suggestion for the designers and engineers are given.

\section{Model of multi-DGs system and principle of damping system oscillation}

The system with multi-DGs discussed in this paper is the power system with the wind farm in particular. The wind turbine in the wind farm is DFIG.

\subsection{The model of the system with DGs}

When the stator voltage vector of DFIG is the q axis, the state equations of DFIG are defined as follows:

$$
\left\{\begin{array}{c}
D \psi_{d s}=-\frac{R_{s}}{L_{s}} \psi_{d s}+\frac{L_{m}}{L_{s}} R_{s} i_{d r}+\omega_{g} \psi_{q s} \\
D \psi_{q s}=-\frac{R_{s}}{L_{s}} \psi_{q s}+\frac{L_{m}}{L_{s}} R_{s} i_{q r}-\omega_{g} \psi_{d s}+u_{q s} \\
D\left(L_{r}-\frac{L_{m}^{2}}{L_{s}}\right) i_{d r}=-R_{r} i_{d r}+u_{d r}+\omega_{s}\left(L_{r}-\frac{L_{m}^{2}}{L_{s}}\right) i_{q r}+ \\
\quad \frac{L_{m}}{L_{s}} \omega_{s} \psi_{q s}-\frac{L_{m}}{L_{s}} D \psi_{d s} \\
D\left(L_{r}-\frac{L_{m}^{2}}{L_{s}}\right) i_{q r}=-\frac{R_{r} i_{q r}+u_{q r}-\omega_{s}\left(L_{r}-\frac{L_{m}^{2}}{L_{s}}\right) i_{d r}-}{L_{m}} \omega_{s} \psi_{d s}-\frac{L_{m}}{L_{s}} D \psi_{q s}
\end{array}\right.
$$

where $D$ is the differential operator; $\omega_{g}$ and $\omega_{s}$ present the synchronous angular velocity of the stator and the angular velocity of the slip, respectively. Other variables are defined the same as those in [10].

The most important control units of DFIG are rotor side converter and grid side converter which are connected by the same capacitor to provide DC voltage. The rotor side converter connected with the rotor of DFIG outputs AC voltage whose frequency and amplitude can be adjusted by vector control. Also, the converter can provide the excitation voltage for the generator and realize decoupling of active and reactive power. The block diagram of the rotor side converter is shown in Fig. 1.

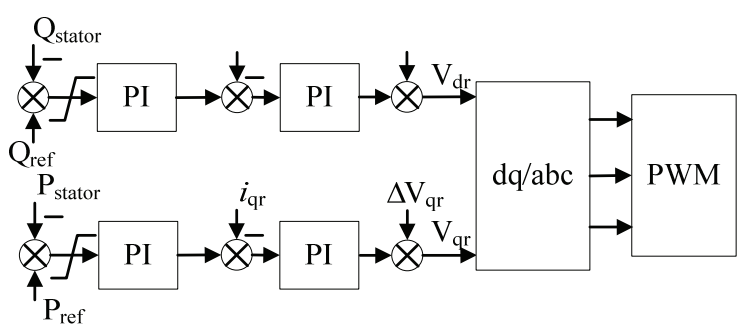

Figure 1 Block diagram of rotor side convertor

In Fig.1, the reactive power of the stator and the reactive power of reference are presented by $Q_{\text {stator }}$ and $Q_{\text {ref }}$, respectively. The active power of the stator and the active power of the reference are presented by $P_{\text {stator }}$ and $P_{\text {ref, }}$, respectively. The rotor current of $d$ axis and that of $q$ axis are presented by $i_{\mathrm{dr}}$ and $i_{\mathrm{qr}}$, respectively. The rotor voltage of $\mathrm{d}$ axis and that of $\mathrm{q}$ axis are presented by $V_{\mathrm{dr}}$ and $V_{\mathrm{qr}}$, respectively. $\Delta V_{\mathrm{dr}}$ and $\Delta V_{\mathrm{qr}}$ are the voltage compensations for eliminating coupling.

The grid side convertor is connected with the power grid and is used to maintain the constant voltage of the capacitor and to adjust power factor. In order to highlight the essence of the problem discussed in this paper, the grid side convertor and capacitor are ignored to simplify the model of the system.

\subsection{The damping properties of the system without DGs}

Whether a wind farm has a positive impact on power system damping, literature $[15 \div 17]$ holds different views. These conclusions are derived from numerical simulation results, the correctness and universality of the conclusions obtained from individual case simulation are questionable. For this reason, this paper will put forward the condition of wind farm to produce positive damping to power system from the angle of analysis, so as to explain the mechanism of damping system oscillation.

Fig. 2 shows the wind-thermal-bundled system. The active power and electric potential amplitude and phase angle of synchronous generator $\mathrm{G}_{1}$ are represented by $p_{e 1}$ and $E \angle \delta_{1}$, respectively. $V_{A} \angle \delta_{A}, V_{B} \angle 0^{\circ}$ present the voltage amplitude and phase angle of node $\mathrm{A}$ and $\mathrm{B}$ respectively; $x_{1}$ presents the reactance between $\mathrm{G}_{1}$ and node $\mathrm{A} ; x_{2}$ presents the reactance between node $\mathrm{A}$ and node $\mathrm{B}$.

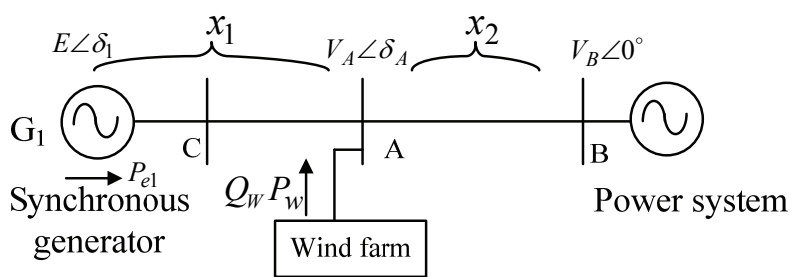

Figure 2 Wind-thermal-bundled power system

Without access to the wind farm, supposing the mechanical input power of synchronous generator is constant, the linearized rotor motion equation of synchronous generator under small-signal can be expressed as:

$\Delta \ddot{\delta}_{1}+\frac{D_{M}}{T_{M}} \Delta \dot{\delta}_{1}+\frac{1}{T_{M}} \Delta P_{e 1}=0$ 
Assuming that $\mathrm{E}$ is constant and ignoring the effect of excitation system, then $\Delta p_{e 1}=K_{1} \Delta \delta_{1}$. Eq. (2) can be obtained by combining $\Delta p_{e 1}$ and Eq. (1).

$$
\Delta \ddot{\delta}_{1}+\frac{D_{M}}{T_{M}} \Delta \dot{\delta}_{1}+\frac{K_{1}}{T_{M}} \Delta \delta_{1}=0
$$

In Eq. (2), $T_{M}$ and $D_{M}$ are respectively the inertia time constant and damping coefficient of synchronous machine;

$$
K_{1}=\frac{\cos \left(\delta_{1(0)}-\delta_{A(0)}\right) \cos \left(\delta_{A(0)}\right)}{\frac{x_{2}}{V_{A} V_{B}} \cos \left(\delta_{1(0)}-\delta_{A(0)}\right)+\frac{x_{1}}{E V_{A}} \cos \left(\delta_{A(0)}\right)} ; \quad \text { the }
$$

subscript (0) represents the initial value.

According to the properties of second-order differential equations, the coefficient $D_{M} / T_{M}$ in Eq. (2) determines the damping of the system. Based on the above assumptions, the system has positive damping property.

\subsection{The damping properties of the system with DGs}

In Fig. 2, the node A is connected to the wind farm. Due to the electromechanical decoupling of wind turbine, the wind farm access does not add new electromechanical oscillation mode. That is, the dominant oscillation mode of the system is still decided by the oscillation mode of the synchronous generator to the infinite system. However, because the wind farm shares the same transmission channel with the conventional power station, the active power increment $\Delta P_{\text {eg }}$ of wind farm will directly impact the electromagnetic power $\Delta P_{e g}$ of the synchronous generator, which will cause the change of the damping of synchronous generator. Then, $\Delta P_{e g}$ shown in Eq. (3) can be derived by the effect of $\Delta P_{e g}$.

$$
\begin{aligned}
& \Delta P_{e 1}=\left[K_{1}+\omega K_{2} \sin (\angle G(j \omega))\right] \Delta \delta_{1}- \\
& \left.-K_{2} \cos (\angle G(j \omega))\right] \Delta \dot{\delta}_{1}
\end{aligned}
$$

Substituting Eq. (3) to Eq.(1) to gain the rotor motion equation of wind farm:

$$
\begin{aligned}
& \Delta \ddot{\delta}_{1}+\left[\frac{D_{M}}{T_{M}}-\frac{K_{2}}{T_{M}} \cos (\angle G(j \omega))\right] \Delta \dot{\delta}_{1}+ \\
& +\left[\frac{K_{1}}{T_{M}}+\frac{\omega K_{2}}{T_{M}} \sin (\angle G(j \omega))\right] \Delta \delta_{1}=0
\end{aligned}
$$

where

$$
K_{2}=\frac{\cos \left(\delta_{1(0)}-\delta_{A(0)}\right)|G(j \omega)|}{\cos \left(\delta_{1(0)}-\delta_{A(0)}\right)+\frac{x_{1} V_{B}}{x_{2} E} \cos \left(\delta_{A(0)}\right)} .
$$

$G(j \omega)$ refers to the definition in [10]: Wind turbine is regarded as a power source controlled by power grid frequency. When the rotor of the synchronous machine has small oscillation, the wind farm can be regarded as a SISO system where $\Delta \omega_{A}$ is input (during small rotor oscillation period, $\left.\Delta \omega_{A}=\Delta \omega_{1}\right)$ and $\Delta P_{e g}$ is output. Then the transfer function of the wind farm is $G(s)=\frac{\Delta P_{e g}(s)}{\Delta \omega_{1}(s)}$. If the oscillation frequency is $\omega$, then $G(j \omega)=\frac{\Delta P_{e g}(j \omega)}{\Delta \omega_{1}(j \omega)}$, where $|G(j \omega)|$ and $\angle G(j \omega)$ express the amplitude and phase angle of $G(j \omega)$ respectively.

Through the comparison of Eq. (2) and (4), it can be seen that the damping has changed by $-\frac{K_{2}}{T_{M}} \cos (\angle G(j \omega))$ after the wind farm was connected to the original system. If $\frac{K_{2}}{T_{M}} \cos (\angle G(j \omega))<0$, the system damping is enhanced. Only under this condition, the conclusion that the wind farms provide positive damping for power systems is correct. In addition, synchronous torque has also changed from the original $K_{1}$ to $K_{1}+\omega K_{2} \sin (\angle G(j \omega))$ after connecting to the wind farm If $\omega K_{2} \sin (\angle G(j \omega))>0$, the synchronous torque increases.

\subsection{Conditions for producing positive damping}

Under normal operating conditions, the coefficient $K_{2}$ is greater than zero. Therefore, in order to ensure that the wind farm can supply positive damping and the synchronous torque is not weakened, the following analytical conditions are obtained:

If $90^{\circ}<\angle G(j \omega) \leq 180^{\circ}$, the wind farm produces positive damping to power system; if $\angle G(j \omega)=180^{\circ}$, the positive damping is the strongest. Moreover the larger $|G(j \omega)|$ is, more obvious the influence of the positive damping is. As long as the condition mentioned above is satisfied, the interaction between the wind farm and the power grid definitely maintains development in a favorable direction. It should also be noted that, if $\angle G(j \omega)=90^{\circ}$, the wind farm does not provide any damping.

\section{Technical measures and existing problems 3.1 Additional active power control strategy}

In general, the phase value of the transfer function of the wind farm is in the range of $90^{\circ}$ to $180^{\circ}$ and the modulus of the transfer function is very small. The values of the phase and the modulus are determined by the controller parameters. In order to create the conditions of providing maximum positive damping for the system, the method can be employed by adding additional active power controller.

The control strategy is that an additional controller is added in the active loop of the original generator control system, as shown in Fig. 3. 


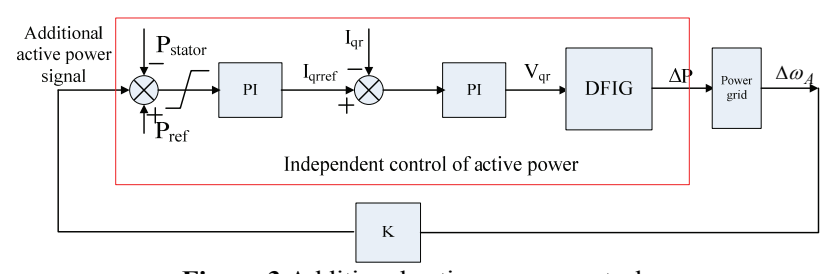

Figure 3 Additional active power controls

In Fig. 3, $\Delta \omega_{A}$ is the frequency increment collected from PCC of the wind farm and is considered as the additional control signal of the wind turbine generators which is transported to the generator's autonomous control loop for adjusting the active power. Because the wind farm consists of multiple wind turbines, each wind turbine can regulate independently the active power at the same time under the action of the additional active controller. Meanwhile, the amplitude-frequency characteristic and phase-frequency characteristic of the entire wind farm can be changed. Using this control strategy to improve the frequency characteristics of the wind farm, the input signal participation can be increased by proportional coefficient $K$ (the choice of which depends mainly on the design experience) in the proportional component, so as to satisfy the conditions of positive damping.

\subsection{Technical measures of additional active power control strategy}

On the basis of the principle mentioned in section 2, the system with the additional active power controller in wide area for the wind farm, which is composed of distributed industrial communication network, is shown in Fig. 4.

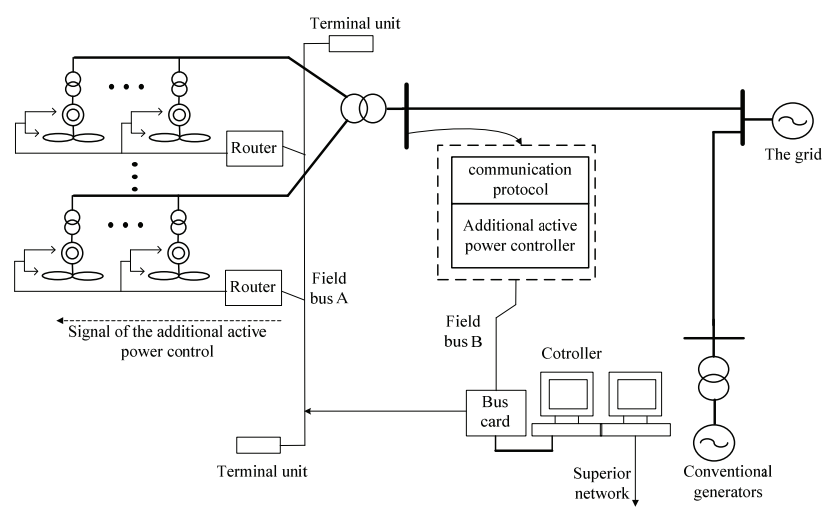

Figure 4 Wide-area additional active power control system

In Fig. 4 the controller is installed near the point of common coupling (PCC) in the wind farm and is used to measure the grid frequency which is the local signal. The frequency is input in the controller to be compared with the reference signal, and then the signal is amplified and filtered. After the phase compensation, the output signal is sent to each wind turbine to adjust the output active power of the wind farm.

Meanwhile, the field bus local area network including router and photoelectric conversion and other hardware equipment is constructed, and the appropriate communication protocol and communication protocol are set up for the efficient communication between the wind farm and the control centre. CAN bus or RS485 can be used as field bus and single-mode optical fibre can be used as the communication medium. Due to the industrial communication technology being more mature and to the low cost of equipment, it is technically possible to achieve the active power control system in wide area. It should be noted that the open inverter communication interface and provision of a standard read-write communication services are a key to the realization of the project.

\subsection{Existing problems}

The additional active controller is usually installed near the public bus and each wind turbine is located in the area of dozens or even hundreds of kilometres. Thus a different time-delay must exist when the signals are collected and transmitted. It was pointed out in $[12,13]$ that the time-delay in the control loop is the primary cause which leads to system instability and poor system performance. In other words, a small time-lag may cause the controller to fail even if the controller holds the superior performance in power system without time-lag. From this point of view, the time-lag is an important factor which ensures whether the additional active power controller works effectively or not. Therefore, the study on the influence of time-lag on additional active power control and the time-lag range that the system can withstand is the basis on which to judge whether the controller is effective or not.

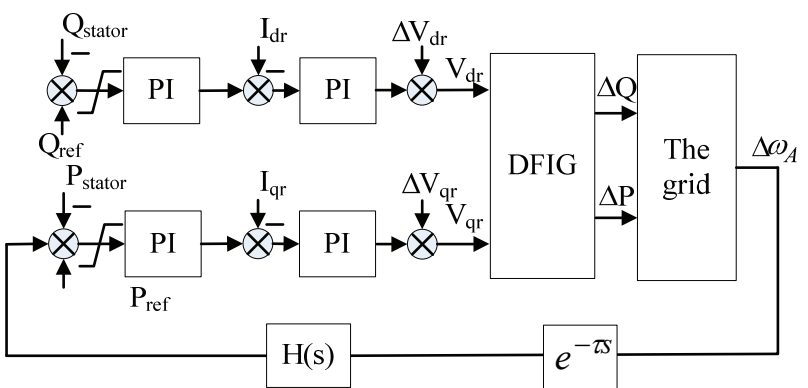

Figure 5 Excitation controller based on influence of time-delay in additional contro

The block diagram shown in Fig. 5 is the excitation controller of the $i^{\text {th }}$ wind turbine considering the communication time-delay where $H(s)$ represents the transfer function of the additional active power controller; $e-\tau s$ represents the time-delay unit in the feedback channel and shows the impact of the communication time-delay on the system. The delay phase $\omega \tau$ is introduced in the feedback part for the time-delay to change the phase of the transfer function and directly influence the control effect.

\section{Influence of time-lag on controller of DGs}

In this paper, the time-lag is the control lag which has obvious influence on the damping of the system, which is mainly reflected in $\Delta P_{e g}$. Therefore, supposing there is a time lag in dynamic active injection of PCC, it can be gained from Eq. (4): 


$$
\begin{array}{r}
\Delta \ddot{\delta}_{1}+\frac{D_{M}}{T_{M}} \Delta \dot{\delta}_{1}+\frac{K_{1}}{T_{M}} \Delta \delta_{1}-\frac{K_{2}}{T_{M}} \cos (\angle G(j \omega)) \Delta \dot{\delta}_{1}(t-\tau) \\
+\frac{\omega K_{2}}{T_{M}} \sin (\angle G(j \omega)) \Delta \delta_{1}(t-\tau)=0
\end{array}
$$

The system damping cannot be directly gained like Eq. (2) and Eq. (4) in the second- order differential equation with time-lag, so the analysis of system eigenvalues needs to be carried out by characteristic method. Only in this way can the strength of the system damping be estimated. So the system state equation with time-lag is built by arranging Eq. (5) and is shown in Eq. (6).

$$
\dot{X}=A X+A_{\tau} X_{\tau}
$$

where

$$
\begin{aligned}
& X=\left[\begin{array}{ll}
\Delta \delta_{1} & \Delta \omega_{1}
\end{array}\right]^{\mathrm{T}} ; \Delta \dot{\delta}_{1}=\Delta \omega_{1} ; \\
& X_{\tau}=\left[\begin{array}{ll}
\Delta \delta_{1}(t-\tau) & \Delta \omega_{1}(t-\tau)
\end{array}\right]^{\mathrm{T}} ; \\
& A=\left[\begin{array}{cc}
0 & 1 \\
-\frac{K_{1}}{T_{M}} & -\frac{D_{M}}{T_{M}}
\end{array}\right] ; \\
& A_{\tau}=\left[\begin{array}{cc}
0 & 0 K_{2} \\
-\frac{T_{M}}{T_{M}} \sin (\angle G(j \omega)) & \frac{K_{2}}{T_{M}} \cos (\angle G(j \omega))
\end{array}\right]
\end{aligned}
$$

Then, the characteristic equation can be written as Eq.

$$
\operatorname{det}\left(\lambda I-A-A_{\tau} e^{-\lambda \tau}\right)=0
$$

Eq. (7) is a transcendental equation with exponential function and the number of characteristic roots is infinite. It has been proved in [12] that: When the time lag of control system is increased to a certain extent, the characteristic equation will derive risk characteristic roots which induce the system instability. That is to say, the time-delay of active power in wind farm may affect the eigenvalue distribution of the system and large time-lag must cause negative damping and destroy the system stability.

\section{Determination of critical time-delay}

Supposing $\tau=0$ (no time-lag), the damping of the system with the wind farm is positive; if $\tau=\tau_{c r i}$, one of the characteristic roots of the system expressed by Eq.(6) is located on the imaginary axis; when $\tau>\tau_{c r i}$, at least one characteristic root enters into the right half plane of the complex plane, then $\tau_{c r i}$ is called the critical timedelay. In this paper, if the time-lag of the additional control causes the system damping to weaken, the critical time-delay is called the time-delay of additional zero damping; if the time-lag of the additional control causes the system damping to be negative, the critical time- lag is called the time- delay of zero-damping system.
Definition 1: The time-delay of additional zero damping $\tau_{r}$ : under additional control, if $\tau=\tau_{r}$ and the system damping is equal to $D_{M} / T_{M}$, then the wind farm provides zero damping; if $\tau>\tau_{r}$ and the system damping is less than $D_{M} / T_{M}$, then the wind farm provides negative damping; if $\tau<\tau_{r}$ and the system damping is more than $D_{M} / T_{M}$, then the wind farm provides positive damping.

Definition 2: The time-delay of zero-damping system $\tau_{w}$ : under additional control, if $\tau=\tau_{w}$ and the system damping is equal to 0 , then the system is in critical stability; if $\tau>\tau_{w}$ and the system damping is less than 0 , then the system is in instability; if $\tau<\tau_{w}$ and the system damping is more than 0 , then the system is in stability.

If $\tau_{r}$ and $\tau_{w}$ can be solved, the maximum time-delay which the stable system allows would be calculated. The maximum time-delay solved can be as the constraint condition to design the additional active power controller that can avoid the negative impact of the wind farm on the system damping. It is given by the following proposition to calculate $\tau_{r}$ and $\tau_{w}$.

Theorem 1: The characteristic value of the system at the equilibrium point is a pure imaginary root, then, the system at this point is critically stable and the system damping is equal to 0 [13].

Proposition 1: The additional active control strategy is adopted in the zero-damping system with the wind farm. With the time-delay increasing, there are characteristic values $\lambda= \pm j \beta_{r}$, and then the critical time-delay of additional zero damping of the wind farm is

$\tau_{r}=\frac{1}{\beta_{r}} \arctan [-\cot (\angle G(j \omega))]$

Proposition 2: The additional active control strategy is adopted in the positive-damping system with the wind farm. With the time-delay increasing, there are characteristic values $\lambda= \pm j \beta_{w}$, then the critical timedelay of zero-damping system is

$\tau_{w}=\frac{1}{\beta_{w}} \arctan \left[\frac{\left(\frac{D_{M}}{T_{M}} \beta_{w}-\beta_{w}^{2}\right) \sin (\angle G(j \omega))-\frac{K_{1}}{T_{M}} \cos (\angle G(j \omega))}{\left(\beta_{w}^{2}-\frac{K_{1}}{T_{M}}\right) \sin (\angle G(j \omega))+\frac{D_{M}}{T_{M}} \beta_{w} \cos (\angle G(j \omega))}\right]$

The proving process of the above statement can be seen in Appendix A and in Appendix B.

It needs to be explained that the time lag $\tau_{r}$ calculated by proposition 1 is the critical time lag in which the wind farm no longer provides positive damping. Therefore, when the time-lag is above $\tau_{r}$, the oscillation amplitude of power angle is increasing and the decay time is prolonged but the system damping is still positive. With the time lag increasing continually, the weakening of damping will be aggravated. The $\tau_{w}$ solved by proposition 2 is the critical time lag when the system eigenvalue has Hopf bifurcation. Once the time lag is 
above $\tau_{w}$, the power angle of the synchronous generator would oscillate with amplitude increasing.

\section{Simulation studies}

In order to test the effect of additional active power controller and the correctness of the above proposition, MATLAB/SIMULINK is used to build the system shown in Fig. 6. The parameters of synchronous generator $G_{1}$ can be seen in Appendix C. The wind farm is simulated by 3 sets of DFIG, and the parameters of DFIG can be seen in [14].

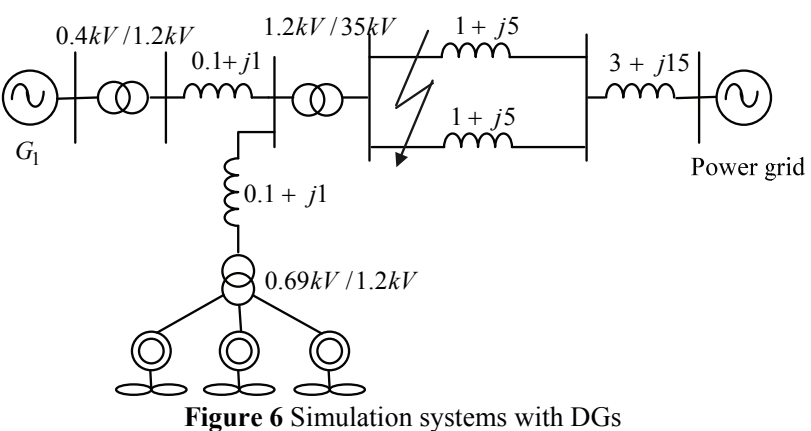

\subsection{Effect of additional active power control on damping}

After the wind farm is connected to the wind farm, the increment of the frequency feedback from PCC of the wind farm is used as the control signal to adjust the active power of each wind turbine. The frequency characteristics of the wind farm are identified by the system identification method. The curves of the frequency characteristics are shown in Fig. 7.
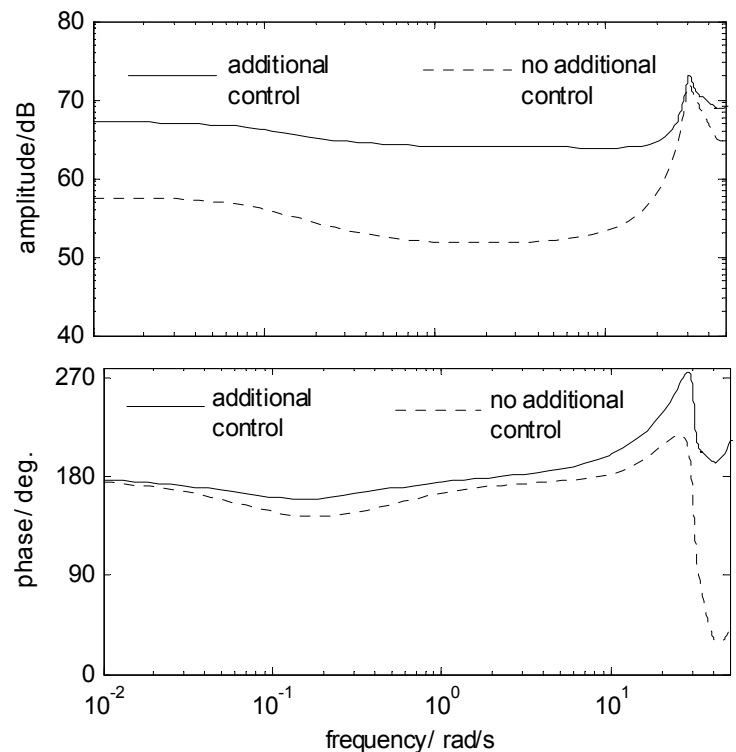

Figure 7 Frequency characteristics of the system with different control strategies

When the rotor of the synchronous machine has small oscillation, the oscillation frequency without additional control is $1,5 \mathrm{rad} / \mathrm{s}$ and the oscillation frequency with additional control is $1,45 \mathrm{rad} / \mathrm{s}$. Meanwhile, under the same oscillation frequency, the phase-frequency characteristic $\angle G(j \omega)$ with additional control is closer to $180^{\circ}$ and the amplitude-frequency characteristic $|G(j \omega)|$ is also larger. Fig. 8 shows the swing curves of the G1's power angle in the two different kinds of cases. It can be known that the swing duration of the power angle without additional control is longer and the swing amplitude is greater. This phenomenon indicates that the system frequency characteristics and the system damping can be improved by feedback of the frequency increment of PCC.

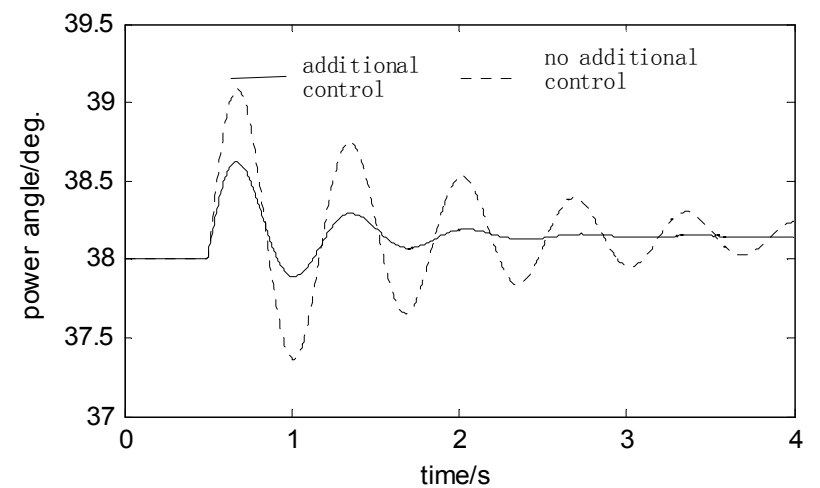

Figure 8 Oscillation curves of $G_{1}$ 's power angle

\subsection{Effect of time delay on system damping}

Set the time lag of the controller increasing from $0 \mathrm{~ms}$ to $230 \mathrm{~ms}$, the generators' power angle and active power output curve can be observed, and then the dominant eigenvalue distribution and the changing rules of the damping ratio shown in Fig. 9 can be gained by Prony analysis.

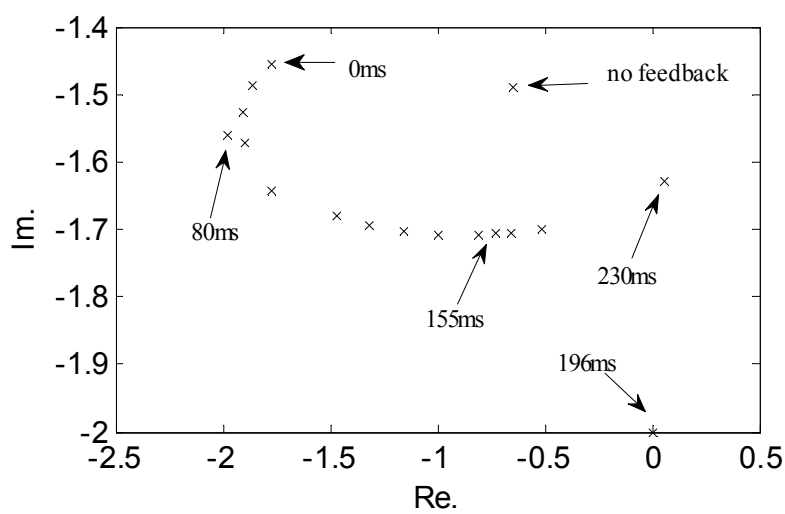

(a) Eigenvalue distribution

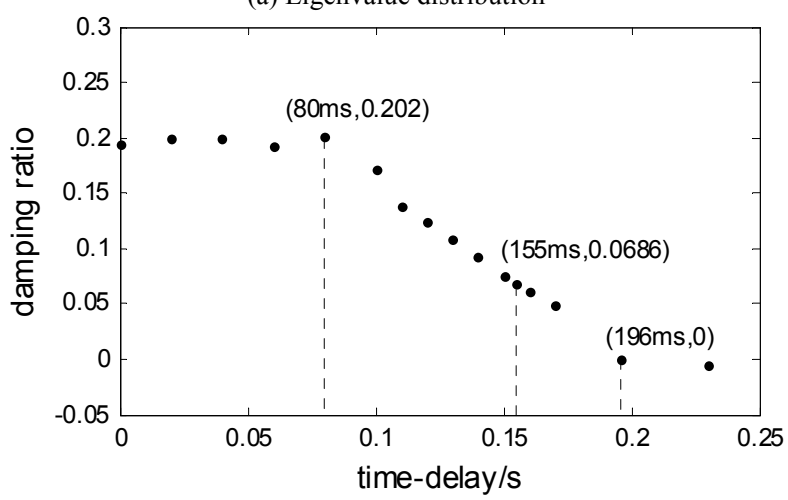

(b) Damping ratio

Figure 9 System eigenvalues and relationship between damping ratio and time-delay 
In Fig. 9a, it can be seen that the eigenvalue with feedback (when $\tau=0 \mathrm{~ms}$ ) has apparent left shift than the eigenvalue without additional control (no feedback).With the time-delay increasing, the eigenvalues continue to move left. Especially when the time-delay is $80 \mathrm{~ms}$, the absolute value of the real value of the eigenvalue reaches the maximum. From Fig. 9b, it can be also seen that the damping ratio reaches the maximum under the same timelag. This phenomenon can be explained as the following: the appearance of the control time-lag has changed the frequency characteristics of the wind farm. And when the time-lag is $80 \mathrm{~ms}$, the phase and amplitude conditions for getting the maximum positive damping of the wind farm are just to be met. However, when the time-lag is more than $80 \mathrm{~ms}$, the characteristic value begins to move to the right. As long as the time-lag is equal to (or above) 230 $\mathrm{ms}$, the real part of the dominant eigenvalue must be greater than 0 .
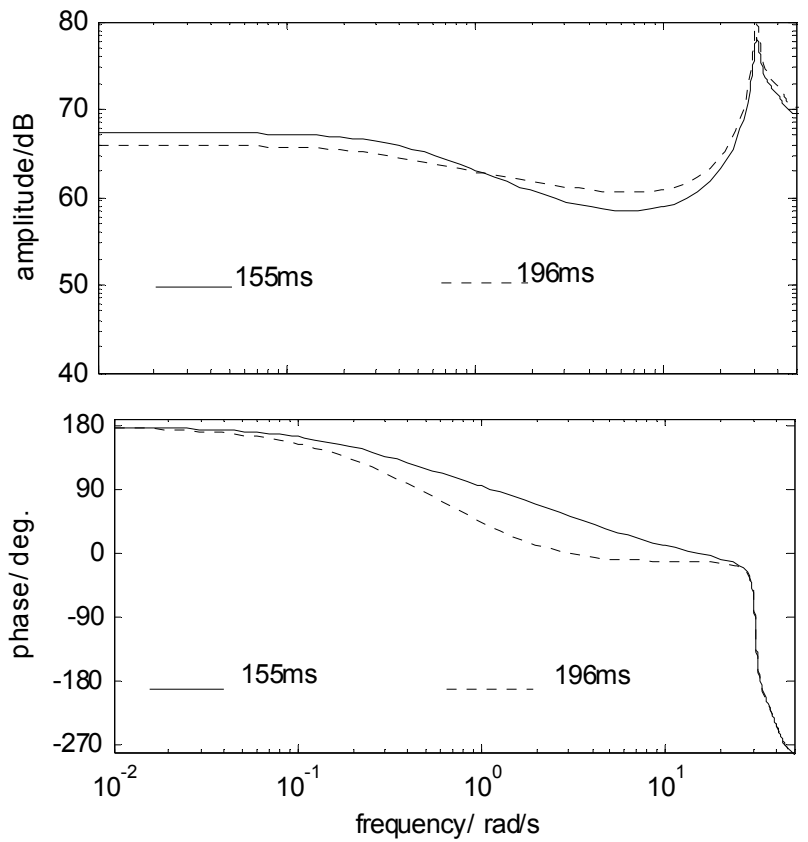

Figure 10 Frequency characteristics of the system with different timedelay

The critical time-lag can be calculated by using the method in the $5^{\text {th }}$ section, so $\tau_{r}=155 \mathrm{~ms}$ and $\tau_{w}=196 \mathrm{~ms}$ are obtained respectively. The control time-lag of the simulation example in this paper is set to $155 \mathrm{~ms}$ and then the damping ratio is gained 0,0686 shown in Fig. 9b. Meanwhile, the system damping ratio without the wind farm is exactly equal to 0,0688 . At this point, the system damping with the wind farm is equivalent to that without the wind farm since the system is in the critical state of the wind farm providing zero damping. When the control time-lag is set to $196 \mathrm{~ms}$, the system eigenvalues are pure imaginary roots and the damping ratio is 0 (shown in Fig. 9), which indicates that the negative damping provided by the wind farm offsets the natural damping of the synchronous machine to 0 and the system is critically stable. It can be seen in the phase frequency characteristics shown in Fig. 10 that the oscillation frequency is $1,7 \mathrm{rad} / \mathrm{s}$ and the corresponding phase is $90^{\circ}$ when $\tau=155 \mathrm{~ms}$. Now the wind farm provides zero damping torque. When $\tau=196 \mathrm{~ms}$, the oscillation frequency is $2 \mathrm{rad} / \mathrm{s}$ and the corresponding phase is $0^{\circ}$.

The curves of the power angle when the time-lags are $155 \mathrm{~ms}$ and $196 \mathrm{~ms}$ are also given in Fig. 11. Obviously, when $\tau_{w}=196 \mathrm{~ms}$, the curve shows constant amplitude oscillation; when the time-lag is less than $\tau_{w}$, it shows weakening oscillation. If the time-lag is increasing constantly, the power angle must fluctuate according to the rule of divergent oscillation.

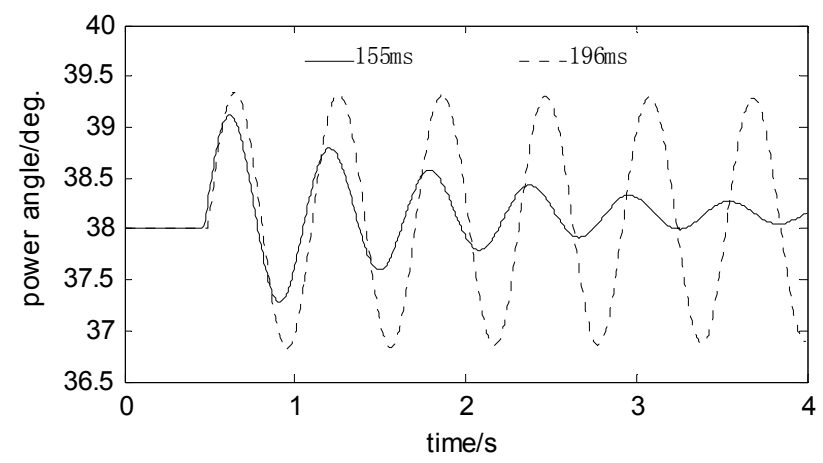

Figure 11 Curves of power angle oscillation in various time-delays

\section{Conclusion}

By taking the frequency feedback from PCC of the wind farm as the control signal of additional active power controller, the oscillation of the power angle of the synchronous generator in the wind-thermal-bundled power system was suppressed reliably and the system damping was effectively improved. Moreover, the correctness and validity of the positive damping condition of the wind farm were verified. When there was a large time-lag during the control signal transmission in the additional active power control system, the time-delay significantly affected the damping contribution of the wind farm to the power system. However, the system damping was not always immediately weakened while the time-lag was decreased; instead, it increased first and then decreased with the increase of time-delay. Through the calculation of the critical time-lag, we can know how the control time-lags affected the wind farm to provide the positive and negative damping. Therefore, when the additional active power controller system is designed, the time-lag range should be taken as the constraint condition to ensure the wind farm providing positive damping.

\section{Acknowledgement}

The authors gratefully acknowledge the support of the National Natural Science Fund of China (51567005), and Introduce Talents Research Fund of Guizhou University (2014-07) and Feng Neng Science and Technology Development Co., Ltd.

\section{References}

[1] Munoz-Cruzado-Alba, J.; Villegas-Nunez, J.; Vite-Frias, J. A.; Carrasco-Solis, J. M.; Galvan-Diez, E. New LowDistortion Q-f Droop Plus Correlation Anti-Islanding Detection Method for Power Converters in Distributed Generation Systems. // IEEE transactions on industrial 
electronics. $\quad 62, \quad 8(2015), \quad$ pp. 5072-5081. DOl: 10.1109/TIE.2015.2405894

[2] Zendehdel, N.; Yazdi, R. A. G. A novel model for smart grid as a network of networks with hybrid composite cross layer description. // Tehnicki vjesnik-Technical Gazette. 22, 1(2015), pp. 133-143. DOI: 10.17559/TV-20140228191043

[3] Li, H.; Ren, Y.; Li, L.; Luo, Z. Application of synchronous grid-connected controller in the wind-solar-storage micro grid. // Tehnički vjesnik-Technical Gazette. 23, 1(2016). DOI: 10.17559/TV-20160108191624

[4] Abdoune, F.; Aouzellag, D.; Ghedamsi, K. Terminal voltage build-up and control of a DFIG based stand-alone wind energy conversion system. // Renewable energy. 97, 11(2016), pp. 468-480. DOI: 10.1016/j.renene.2016.06.005

[5] Ma, R.; Yang, W. C.; Li, M. Research on Voltage Stability Boundary under Different Reactive Power Control Mode of DFIG Wind Power Plant. // Journal of Electrical Engineering \& Technology. 11, 6(2016), pp. 1571-1581. DOI: 10.5370/JEET.2016.11.6.1571

[6] Kang, M.; Kim, K.; Muljadi, E.; Park, J. W.; Kang, Y. C. Frequency Control Support of a Doubly-Fed Induction Generator Based on the Torque Limit. // IEEE Transactions on Power Systems. 31, 6(2016), pp. 4575-4583. DOl: 10.1109/TPWRS.2015.2514240

[7] Kim, J.; Muljadi, E.; Park, J. W.; Kang, Y. C.; Adaptive Hierarchical Voltage Control of a DFIG-Based Wind Power Plant for a Grid Fault. // IEEE Transactions on Smart Grid. 7, 6(2016), pp. 2980-2990. DOI: 10.1109/TSG.2016.2562111

[8] Mehdipour, C.; Hajizadeh, A.; Mehdipour, I. Dynamic modeling and control of DFIG-based wind turbines under balanced network conditions.// International Journal of Electrical Power \& Energy Systems, 12, (2016), pp. 560569. DOI: 10.1016/j.jijepes.2016.04.046

[9] Edrah, M.; Lo, K. L.; Anaya-Lara, O. Reactive power control of DFIG wind turbines for power oscillation damping under a wide range of operating conditions. // IET Generation Transmission \& Distribution. 10, 15(2016), pp. 3777-3785. DOI: 10.1049/iet-gtd.2016.0132

[10] Hao, Z. H.; Yao, Z. Q.; Li, S. H.; Zhang, AL.; Chen, Z.; Chai, JY. The contribution of double-fed wind farms to transient voltage and damping of power grids. // Tehnicki vjesnik-Technical Gazette. 22, 1(2015), pp. 43-49. DOl: 10.17559/TV-20150209230644

[11] Zhiqing, Y.; Zhenghang, H.; Zhuo, C. Coordinated Stability Control of Wind-Thermal Hybrid AC/DC Power System. // Mathematical Problems in Engineering. 22, 1(2016), pp. 19.

[12] Chen, Z.; Hao Z. H.; Qin, Sj. Centralized Reactive Power Control for a Wind Farm under Impact of Communication Delay. // International Journal of Control and Automation. 7, 2(2014), pp. 85-98. DOI: 10.14257/ijca.2014.7.2.09

[13] Chen, Z.; Hao Z. H.; Zhang, Z. P. Further-inspection for Doubly-Fed Converter: Theory, Method and Experimental Platform. // International Journal of Control and Automation. 7, 6(2014), pp. 51-64.

[14] Zhuo, C.; Hongjun, Z.; Qingfang, Z.; Yan, L. Research on the impact of double-fed wind turbine generator drive system modeling on torsional vibration frequency. // The 3 rd international conference on engineering technology and application / Kyoto · Japan, 2016, pp. 578-585.

[15] Dosoglu, M. K. A new approach for low voltage ride through capability in DFIG based wind farm. // International journal of electrical power \& energy systems. 83, 12(2016), pp. 251-258. DOI: 10.1016/j.ijepes.2016.04.027

[16] Zhu, R. W.; Deng, F. J.; Chen, Z.; Liserre, M. Enhanced Control of DFIG Wind Turbine Based on Stator Flux Decay Compensation. // IEEE transactions on energy conversion. 31, 412(2016), pp. 1366-1376. DOl: 10.1109/TEC.2016.2594014
[17] Edrah, M.; Lo, K. L.; Anaya-Lara, O. Reactive power control of DFIG wind turbines for power oscillation damping under a wide range of operating conditions. // IET generation transmission \& distribution. 10, 15(2016), pp. 3777-3785. DOI: 10.1049/iet-gtd.2016.0132

\section{Appendix \\ Appendix A: Proof of proposition 1}

Let $D_{M}=0$, then the system damping with the wind farm is determined only by the electrical damping provided by the wind farm.

If the time delay is $\tau$, the eigenvalues of the system are $\lambda= \pm j \beta_{r}$. According to theorem 1 , the time delay $\tau$ is the critical time delay of additional zero-damping $\left(\tau_{r}\right)$.

To expand Eq. (7):

$$
\begin{aligned}
\left(\lambda^{2}+\frac{K_{1}}{T_{M}}\right)+e^{-\lambda \tau_{r}}\left[-\frac{K_{2}}{T_{M}}\right. & \cos (\angle G(j \omega)) \lambda+ \\
& \left.+\frac{\omega K_{2}}{T_{M}} \sin (\angle G(j \omega))\right]=0
\end{aligned}
$$

Substituting $\lambda=-j \beta_{r}$ into Eq. (8), Eq. (A-2) can be obtained.

$$
e^{j \beta_{r} \tau_{r}}=\frac{\beta_{r}\left(-T_{M} \beta_{r}^{2}+K_{1}\right)[\sin (\angle G(j \omega))-j \cos (\angle G(j \omega)]}{K_{2}\left[\sin ^{2}(\angle G(j \omega))+\beta_{r}^{2} \cos ^{2}(\angle G(j \omega))\right]}(\mathrm{A}-2)
$$

So the critical time-delay of the additional zerodamping for the system is shown in Eq. (A-3).

$$
\tau_{r}=\frac{1}{\beta_{r}} \arctan [-\cot (\angle G(j \omega))]
$$

Otherwise, we need to calculate $\beta_{r}$. Substituting $\lambda= \pm j \beta_{r}$ into Eq. (A-1) and eliminating the exponential function term, we get the polynomial equation for $\beta_{r}$ : $\beta_{r}^{4}-\left[\frac{2 K_{1}}{T_{M}}+\frac{K_{2}^{2}}{T_{M}^{2}} \cos ^{2}(\angle G(j \omega))\right] \beta_{r}^{2}+\frac{K_{2}^{2}}{T_{M}^{2}} \sin ^{2}(\angle G(j \omega))=0$ Then $\beta=\left\{\beta_{r 1}, \beta_{r 2}, \beta_{r 3}, \beta_{r 4}\right\}$ can be obtained and plug it into (A-3). We can get $\left\{\tau_{r 1}, \tau_{r 2}, \tau_{r 3}, \tau_{r 4}\right\}$ and select $\tau=\min \left\{\tau_{r 1}\right.$, $\left.\tau_{r 2}, \tau_{r 3}, \tau_{r 4}\right\}$.

Proof finished.

\section{Appendix B: Proof of proposition 2}

It is similar to Proof of Proposition 1. When the timedelay is $\tau$ under the condition of $\mathrm{D}_{\mathrm{M}} \neq 0$, the system eigenvalues are $\lambda= \pm j \beta_{w}$. According to theorem 1, it indicates that the system is in critical stability, and then the time delay $\tau$ is the critical delay of the zero-damping system $\left(\tau_{w}\right)$.

Expanding Eq. (7), we can get:

$$
\begin{aligned}
\left(\lambda^{2}+\frac{D_{M}}{T_{M}} \lambda+\frac{K_{1}}{T_{M}}\right)+e^{-\lambda \tau_{r}}[ & -\frac{K_{2}}{T_{M}} \cos (\angle G(j \omega)) \lambda \\
& \left.+\frac{\omega K_{2}}{T_{M}} \sin (\angle G(j \omega))\right]=0(\mathrm{~A}-4)
\end{aligned}
$$


Substituting $\lambda=-j \beta_{w}$ into Eq. (8), Eq. (A-5) can be obtained.

$\tau_{w}=\frac{1}{\beta_{w}} \arctan \left[\frac{\left(\frac{D_{M}}{T_{M}} \beta_{w}-\beta_{w}^{2}\right) \sin (\angle G(j \omega))-\frac{K_{1}}{T_{M}} \cos (\angle G(j \omega))}{\left(\beta_{w}^{2}-\frac{K_{1}}{T_{M}}\right) \sin (\angle G(j \omega))+\frac{D_{M}}{T_{M}} \beta_{w} \cos (\angle G(j \omega))}\right](\mathrm{A}-5)$

Otherwise, we need to calculate $\beta_{w}$. Substituting $\lambda= \pm \mathrm{j} \beta_{w}$ into Eq. (A-1) and eliminating the exponential function term, we get the polynomial equation for $\beta_{w}$ :

$$
\begin{array}{r}
\beta_{w}^{4}-\left[\frac{2 K_{1}}{T_{M}}+\frac{K_{2}^{2}}{T_{M}^{2}} \cos ^{2}(\angle G(j \omega))-\frac{D_{M}^{2}}{T_{M}^{2}}\right] \beta_{w}^{2}+ \\
+\left[\frac{K_{1}^{2}}{T_{M}^{2}}+\frac{K_{2}^{2}}{T_{M}^{2}} \sin ^{2}(\angle G(j \omega))\right]=0
\end{array}
$$

Then $\beta_{w}=\left\{\beta_{w 1}, \beta_{w 2}, \beta_{w 3}, \beta_{w 4}\right\}$ can be obtained and plug it into (A-5). We can get $\left\{\tau_{w 1}, \tau_{w 2}, \tau_{w 3}, \tau_{w 4}\right\}$ and select $\tau=\min \left\{\tau_{w 1}, \tau_{w 2}, \tau_{w 3}, \tau_{w 4}\right\}$.

Proof finished.

\section{Appendix C: Parameters of synchronous generator}

$X_{d}=1,2, X_{d}^{\prime}=0,15, X_{d}^{\prime \prime}=0,13, X_{q}=1,2, X_{q}^{\prime \prime}=0,13$, $T_{M}=8 \mathrm{~s}, T_{d 0}=8,940 \mathrm{~s}, T_{d 0}{ }^{\prime \prime}=0,093 \mathrm{~s}, T_{q 0}{ }^{\prime \prime}=0,150 \mathrm{~s}, T_{e}=$ $0,01 \mathrm{~s}, D_{M}=0,8$.

\section{Authors' addresses}

Zhuo Chen, Prof. Dr.

Guizhou University,

College of Electrical Engineering,

Guizhou Key Laboratory of Electric Power Big Data,

Guizhou Institute of Technology,

Guiyang, China

Zip Code: 550025

E-mail: chzh1230@163.com

\section{Xuanqun Tang}

Guizhou University,

College of Electrical Engineering,

Guiyang, China

Zip Code: 550025

\section{Hongjun Zhang}

Guizhou University,

College of Electrical Engineering,

Guiyang, China

Zip Code: 550025

\section{Qingfang Zhang}

Guizhou University,

College of Electrical Engineering,

Guiyang, China

Zip Code: 550025

\section{Yan Liu}

Guizhou University,

College of Electrical Engineering,

Guiyang, China

Zip Code: 550025 